\title{
Primary Myelofibrosis in the Prefibrotic Stage Presenting as Portal, Splenic, and Superior Mesenteric Vein Thrombosis: A Case Report and Review of the Literature
}

\author{
Emanuel Dias $^{a}$ Rodrigo Liberal ${ }^{a}$ Pedro Costa-Moreira ${ }^{a}$ Fernando Príncipe ${ }^{b}$ \\ Elsa Fonsecac Guilherme Macedo ${ }^{\mathrm{a}}$

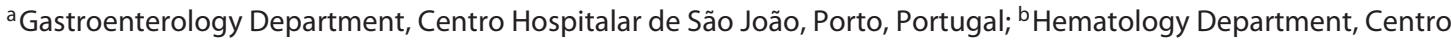 \\ Hospitalar de São João, Porto, Portugal; ' Pathology Department, Centro Hospitalar de São João, Porto, Portugal
}

\section{Keywords}

Myeloproliferative neoplasm · Primary myelofibrosis · Portal vein thrombosis . Splanchnic vein thrombosis

\section{Abstract}

Introduction: Myeloproliferative neoplasms are the most common cause of splanchnic vein thrombosis in the absence of cirrhosis or nearby malignancy. Case Presentation: A 31-year-old male presented to the emergency department with epigastric pain associated with mild thrombocytosis and elevated levels of aminotransferases, lactate dehydrogenase, and C-reactive protein. Contrast-enhanced abdominal computed tomography revealed splanchnic venous thrombosis that involved the portal, splenic, and superior mesenteric veins, without signs of chronic liver disease. Anticoagulation with warfarin was immediately started. Diagnostic work-up was remarkable for the presence of the JAK2 V617T mutation and hypercellular bone marrow, with increased myeloid cells and atypical megakaryocytes, consistent with primary myelofibrosis in a prefibrotic stage. No other hypercoagulable conditions were identified. Discussion: We present a rare case of primary myelofibrosis in the prefibrotic stage presenting as portal-splenic-superior mes- enteric vein thrombosis. This demonstrates that extensive splanchnic vein thrombosis may be the onset manifestation of myeloproliferative neoplasms, even in early stages and in the absence of concomitant hypercoagulable conditions. The presence of the JAK2 mutation is an important prothrombotic risk factor that can, per se, contribute to large venous thrombosis.

(c) 2021 Sociedade Portuguesa de Gastrenterologia Published by S. Karger AG, Basel

Trombose da veia porta, esplénica e mesentérica superior como forma de apresentação de mielofibrose primária em estadio pré-fibrótico: descrição de um caso e revisão da literatura

\section{Palavras Chave}

Neoplasia mieloproliferativa · Mielofibrose primária · Trombose da veia porta . Trombose venosa esplâncnica

\section{Resumo}

Introdução: As neoplasias mieloproliferativas constituem a causa mais comum de trombose venosa esplâncnica na karger@karger.com www.karger.com/pjg

Karger $\stackrel{\text { ' }}{5}$ BOPEN ACCESS

\section{(c) 2021 Sociedade Portuguesa de Gastrenterologia} Published by S. Karger AG, Basel

This is an Open Access article licensed under the Creative Commons Attribution-NonCommercial-4.0 International License (CC BY-NC) (http://www.karger.com/Services/OpenAccessLicense), applicable to the online version of the article only. Usage and distribution for commercial purposes requires written permission.
Correspondence to:

Emanuel Dias, diasj0310@gmail.com 
ausência de cirrose hepatica ou neoplasia regional. Descrição do caso: Um homem de 31 anos apresentou-se no Serviço de Urgência com dor epigástrica associada a trombocitose ligeira e elevação das transamínases, desidrogenase láctica e proteína C-reactiva. Em tomografia computorizada abdominal com contraste, foi identificada trombose venosa esplâncnica envolvendo a veia porta, esplénica e mesentérica superior, sem sinais de doença hepática crónica. Foi de imediato iniciada anticoagulação com varfarina. Da investigação etiológica, destaca-se a presença da mutação JAK2 V617F e medula óssea hipercelular com aumento das contagens de células mielóides e megacariócitos atípicos, consistente com mielofibrose primária em estadio pré-fibrótico. Não se identificaram distúrbios pro-trombóticos concomitantes. Discussão: Apresenta-se um raro caso de trombose da veia porta, esplénica e mesentérica superior, demonstrando que as neoplasias mieloproliferativas podem apresentar-se sob a forma de trombose venosa esplâncnica extensa, mesmo em estadios precoces e na ausência de distúrbios protrombóticos concomitantes. A presença da mutação JAK2 é um importante factor de risco pro-trombótico que pode por si só contribuir para a formação de tromboses venosas extensas.

(C) 2021 Sociedade Portuguesa de Gastrenterologia Publicado por S. Karger AG, Basel

\section{Introduction}

Myeloproliferative neoplasms (MPN) are characterized by clonal proliferation of hematopoietic stem cells, with overproduction of functional granulocytes, erythrocytes, and/or platelets. Classic MPN include polycythemia vera $(\mathrm{PV})$, essential thrombocythemia (ET), primary myelofibrosis (PMF), and chronic myeloid leukemia. One major complication is the occurrence of venous and arterial thrombosis. There is a strong association between MPN and splanchnic vein thrombosis (SVT) [1].

SVT is a rare disorder that encompasses thrombosis formation in the portal, hepatic, splenic, or superior mesenteric venous systems. In a large multicenter study, the estimated incidence rate for portal vein thrombosis was only 0.7 cases per 100,000 patients per year [2]. In a recent meta-analysis, the prevalence of MPN in SVT was approximately $30 \%$ [3]. Given this strong association, screening for MPN is recommended when SVT is diagnosed [3].

Here, we report a rare case of a young male who presented with portal-splenic-superior mesenteric vein thrombosis that was found to be secondary to PMF in the

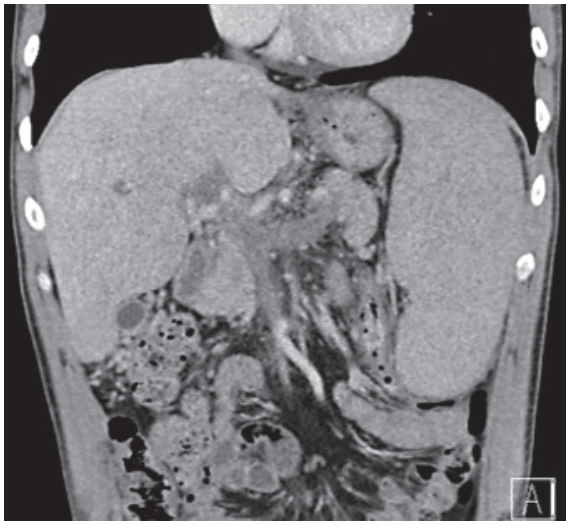

Fig. 1. Contrast-enhanced abdominal computerized tomography image demonstrating extensive splanchnic vein thrombosis involving the portal, splenic, and superior mesenteric veins. The thrombus extends through the splenic vein, almost reaching the splenic hilum, and involving the entire portal vein by extending into its left and right intrahepatic branches. Splenomegaly is also evident, with an enlarged spleen measuring $17.5 \mathrm{~cm}$. No signs of chronic liver disease or suspicious liver nodules were identified.

prefibrotic stage. There is a limited number of cases of MPN presenting as SVT with such extension, especially at early stages. We also performed a literature review on this topic.

\section{Case Presentation}

A 31-year-old male with no significant previous medical history presented to the emergency department with a 3-week history of epigastric pain that radiated to the back and was aggravated after meals. He denied experiencing nausea, vomiting, diarrhea, gastrointestinal bleeding, weight loss, chills, or any other symptoms. Physical examination revealed epigastric tenderness, but without signs of peritoneal inflammation. His general state of health was good. He was afebrile and hemodynamically stable. Laboratory evaluation revealed mild thrombocytosis (a platelet count of $\left.420,000 \times 10^{3} / \mu \mathrm{L}\right)$ associated with elevated levels of alanine aminotransferase $(144 \mathrm{IU} / \mathrm{mL})$, aspartate aminotransferase (93 IU/ $\mathrm{mL})$, lactate dehydrogenase $(609 \mathrm{IU} / \mathrm{mL})$, and C-reactive protein (47.2 mg/L). Hemoglobin, leukocyte count, urea, creatinine, bilirubin, alkaline phosphatase, $\gamma$-glutamyl transferase, amylase, lipase, and coagulation studies were all normal. Contrast-enhanced abdominal computerized tomography (CT) revealed extensive SVT involving the portal, splenic, and superior mesenteric veins (Fig. 1). Splenomegaly was also evident. No signs of chronic liver disease or suspicious liver nodules were identified.

He was admitted and started anticoagulation with warfarin with a target international normalized ratio (INR) of 2.0-3.0. The patient's medical records revealed elevated platelet counts for at least 6 years, with a peak of approximately $673,000 \times 10^{3} / \mu \mathrm{L} 3$ years previously. No significant changes in other blood cells were found. 

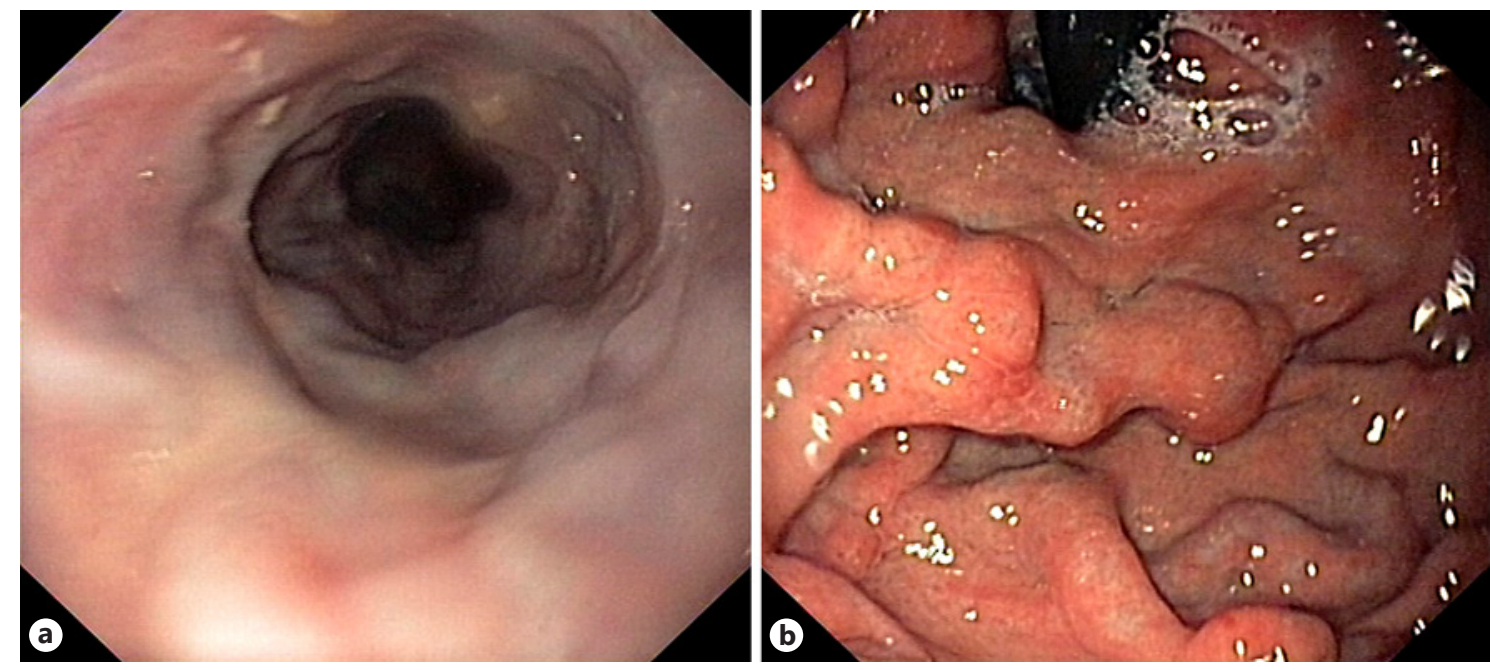

Fig. 2. Upper digestive endoscopy demonstrating signs of portal hypertension. a Large esophageal varices were identified at distal esophagus. b Endoscopic examination of gastric fundus revealed the presence of varices.
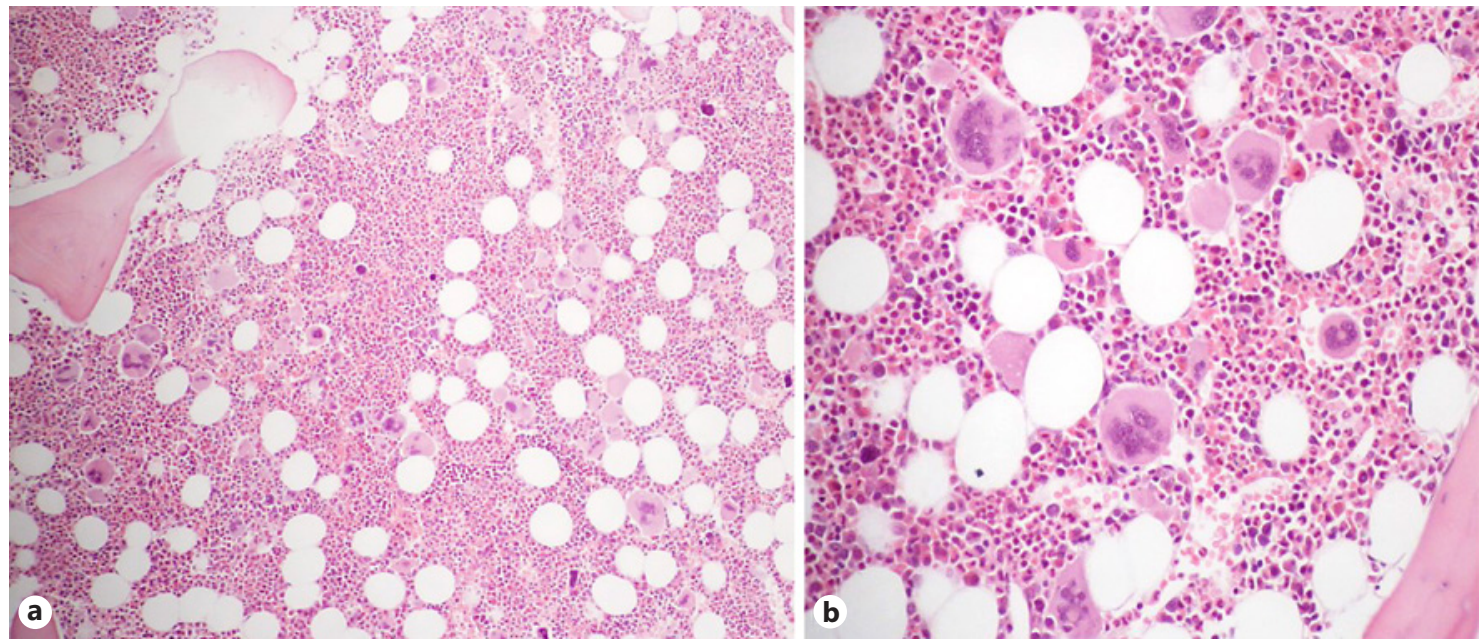

Fig. 3. Histopathological examination of the bone marrow. a Hypercellular bone marrow, with an increased number of myeloid cells and megakaryocytes. H\&E. $\times 100$. b Clusters of atypical megakaryocytes with hyperlobulated "cloud-like" nuclei. H\&E. ×200.

The possibility of a MPN was considered, and so analysis for the $J A K 2$ V617F mutation and a bone marrow biopsy were performed. Lupus anticoagulant, anti-cardiolipin and anti-B2 glycoprotein antibodies were normal. $\alpha$-Fetoprotein was also normal. Esophagogastroduodenoscopy revealed large esophageal (Fig. 2a) and gastric (Fig. 2b) varices. Primary prophylaxis for variceal bleeding with propranolol was started. INR was maintained inside the target range; after 21 days, he was discharged home anticoagulated with warfarin.

The patient was subsequently evaluated at a hematology consultation. Remarkably, the presence of the JAK2 V617F mutation was established. The bone marrow biopsy revealed hypercellularity, with increased proliferation of myeloid and megakaryocytic cell lines and an increased myeloid/erythroid cell ratio (Fig. 3a). There were no maturation abnormalities involving myeloid or erythroid cells. In contrast, atypical megakaryocytes with hyperlobulated hyperchromatic "cloud-like" nuclei were found (Fig. 3b). The reticulin fibers network was focally enhanced, without significant reticulin fibrosis. he was negative for the $B C R / A B L 1$ mutation. These findings were consistent with PMF in a prefibrotic stage. Cytoreductive therapy with weekly subcutaneous pegylated interferon was started. 
Table 1. Summary of previous cases of splanchnic vein thrombosis involving $>1$ of the main splanchnic veins in association with myeloproliferative neoplasms

\begin{tabular}{|c|c|c|c|c|c|c|c|c|c|}
\hline \multirow{2}{*}{$\begin{array}{l}\text { Patient } \\
\text { No. }\end{array}$} & \multirow[t]{2}{*}{ First author [ref.] } & \multirow[t]{2}{*}{ Gender } & \multirow{2}{*}{$\begin{array}{l}\text { Age, } \\
\text { years }\end{array}$} & \multirow{2}{*}{$\begin{array}{l}\text { Myeloproliferative } \\
\text { neoplasm }\end{array}$} & \multicolumn{3}{|c|}{ Splanchnic veins involved } & \multirow{2}{*}{$\begin{array}{l}J A K 2 \\
\text { mutation }\end{array}$} & \multirow{2}{*}{$\begin{array}{l}\text { Concomitant } \\
\text { hypercoagulable } \\
\text { conditions }\end{array}$} \\
\hline & & & & & portal & splenic & $\begin{array}{l}\text { superior } \\
\text { mesenteric }\end{array}$ & & \\
\hline 1 & Chebli [6] & female & 76 & essential thrombocythemia & Yes & Yes & Yes & n.a. & none \\
\hline 2 & Berk [7] & male & 37 & essential thrombocythemia & Yes & Yes & Yes & n.a. & hyperhomocysteinemia \\
\hline 3 & Marisavlevic [8] & female & 27 & essential thrombocythemia & Yes & Yes & Yes & n.a. & protein $\mathrm{C}$ resistance \\
\hline 4 & Macías [9] & male & 55 & essential thrombocythemia & Yes & Yes & No & Yes & none \\
\hline 5 & Vladareanu [10] & male & 29 & essential thrombocythemia & Yes & Yes & No & Yes & none \\
\hline 6 & Vladareanu [10] & male & 54 & polycythemia vera & Yes & Yes & Yes & Yes & none \\
\hline 7 & Vladareanu [10] & male & 53 & unclassifiable & Yes & Yes & Yes & Yes & hereditary spherocytosis \\
\hline 8 & De Suray [11] & male & 49 & polycythemia vera & Yes & No & Yes & Yes & none \\
\hline 9 & Campos-Cabrera [12] & female & 66 & primary myelofibrosis & Yes & No & Yes & Yes & none \\
\hline
\end{tabular}

Approximately 1 month after discharge, he was readmitted for abdominal pain. Abdominal CT still revealed portal-splenic-mesenteric venous thrombosis. Given the stability of the thrombus size despite anticoagulation and therapeutic INR, thrombolysis or shunt placement by interventional radiology were considered; however, the clot burden precluded these approaches. Despite an improvement in abdominal pain, repeat CT after 10 days revealed a stable thrombus size. He was discharged home maintaining warfarin and weekly pegylated interferon.

After these events, the patient evolved favorably with progressive resolution of his symptoms. He maintained anticoagulation and 5 months later, Doppler ultrasound revealed complete dissolution of the thrombus. After 14 months, the patient remains asymptomatic and maintains cytoreductive therapy for his hematological disease and anticoagulation with warfarin for the prophylaxis of recurrent thrombosis.

\section{Discussion}

MPN are the most common underlying prothrombotic disorder found in patients with SVT, in the absence of local factors such as liver cirrhosis or nearby malignancy. Risk factors for MPN-associated SVT include young age, female gender, concomitant hypercoagulable disorders, and the JAK2 V617F mutation. The pathophysiology of SVT is thought to derive from local interactions between atypical blood cells and aberrant splanchnic endothelial cells that increase the likelihood of thrombus formation. SVT may represent the first manifestation of MPN (particularly when the JAK2 V617F mutation is present) and, importantly, it can present with few overt MPN disease characteristics, possibly because it occurs during an early stage or because characteristic erythrocytosis or thrombocytosis may be masked by hypersplenism and hemodilution secondary to portal hypertension [1].
In a retrospective study involving 181 patients with MPN-associated SVT, the thrombus involved the portal vein in $60.3 \%$ of patients, the hepatic vein in $17.1 \%$, the splenic vein in $13 \%$, and the mesenteric vein in $10 \%$ [4]. Another retrospective study involving 84 patients demonstrated that MPN-associated SVT involved the portal vein in $69 \%$ of the cases, and that the thrombus extended to the mesenteric and/or splenic vein in $<20 \%$ of these patients [5]. Although the thrombus extension is usually limited to one of these venous systems, SVT involving more than one of the main splanchnic veins has rarely been described as the onset manifestation of MPN, including ET [6-10], PV [10,11], and PMF [12] cases (summarized in Table 1). In some of these patients, the thrombus extended throughout the portal, splenic, and superior mesenteric venous systems $[6-8,10]$, similar to in our patient. This is a critical clinical situation that may result in severe complications. Abdominal pain resulting from increased venous pressure is almost universal and can be incapacitating. Other serious potential complications include variceal bleeding, ascites or hepatic encephalopathy resulting from portal hypertension $[9,13]$, splenic infarction secondary to splenic vein obstruction [6], and intestinal ischemia secondary to mesenteric vein obstruction [14].

It is also interesting that, although some patients have concomitant hypercoagulable conditions like hyperhomocysteinemia [7] or resistance to activated C protein [8] which can contribute to the large thrombus size, in other cases, the single prothrombotic risk factor was the presence of the JAK2 V617F mutation [9-12], supporting an important role for this mutation in the development of extensive SVT. In one of these cases, SVT involving the portal and superior mesenteric veins was reported as the 
first manifestation of overt PMF [12]. Here, we also report extensive SVT in the form of PMF, but a larger thrombus size (portal, splenic, and superior mesenteric veins), albeit it was detected at an earlier stage of the disease (i.e., the prefibrotic stage). Notably, the patient also did not present with any concomitant hypercoagulable condition besides the JAK2 V617F mutation, which therefore appears to be an important prothrombotic risk factor that can, per se, induce the formation of a large thrombus.

There is little information regarding the variables associated with thrombosis risk in patients with prefibrotic PMF, translating into uncertainty regarding the stratification and management of these patients. Interestingly, in a large retrospective study involving 518 patients with MPN-associated SVT with a reported prevalence of the JAK2 V617F mutation of $90 \%$, the thrombus involved $>1$ of the main splanchnic veins in approximately $30 \%$ of the patients, supporting the notion that JAK2 V617F mutation is per se an important risk factor for thrombosis [15]. However, more than one-third of cases of MPNassociated SVT show at least one coexisting risk factor/ hypercoagulable disorder and, more recently, the presence of high-molecular-risk variants has also been associated with worse prognosis, even in patients with a JAK2positive MPN [16].

Diagnostic criteria for PMF in the prefibrotic stage include: (i) proliferation of atypical megakaryocytes, without significant reticulin fibrosis, accompanied by increased bone marrow cellularity, granulocytic proliferation and, often, decreased erythropoiesis; (ii) not meeting the criteria for other MPN; (iii) the presence of the JAK2, CALR, or MPL mutation. Additionally, at least one minor criterion (anemia, leukocytosis, splenomegaly, or elevated LDH) must be present. Distinction from overt PMF is related to more marked reticulin fibrosis in the latter and from ET because, in this case, megakaryocytes are mature and only very rarely is there minimal reticulin fibrosis [17]. Based on these criteria, this case represents an uncommon clinical scenario where PMF in the prefibrotic stage presented with portal-splenic-superior mesenteric vein thrombosis as the onset manifestation.

It is important to highlight that the survival of patients with MPN-associated SVT is regarded as being influenced primarily by the natural history of the underlying neoplasm, rather than by the recurring thrombotic event and/or the consequences for the splanchnic circulation and liver function. This emphasizes the importance of making a clear distinction between ET and

Splanchnic Vein Thrombosis Associated with Primary Myelofibrosis prefibrotic PMF. However, this may be challenging, since PMF in the prefibrotic stage can mimic ET in its presentation and mutation profile; careful morphologic examination is therefore necessary. While the initial presentation of PMF in the prefibrotic stage is often isolated thrombocytosis, thereby mimicking ET, the course of prefibrotic PMF may be highly symptomatic, and the outcome is worse than in ET. Patients with prefibrotic PMF have higher leukocyte and platelet counts, lower hemoglobin, higher lactate dehydrogenase levels, and more frequently display splenomegaly than patients with ET. In the largest series available, involving 661 patients with prefibrotic PMF, the median overall survival was 14.7 years, significantly shorter than the 30.2 years in a parallel cohort of 421 unselected patients with ET [18].

Therapy should be addressed by pursuing 3 main goals: (a) preventing recurrence of thrombosis; (b) managing the underlying MPN; and (c) supporting organ dysfunction, particularly of the liver. Management of thrombotic complications associated with MPN may be challenging. Although the risk of SVT is higher than in the general population, these patients are also prone to severe bleeding [19]. In general, patients with MPNassociated SVT should be treated promptly with lowmolecular or unfractionated heparin followed by vitamin $\mathrm{K}$ antagonists, maintaining an INR in the therapeutic range of 2.0-3.0. The optimal duration of treatment is unknown, but, in general, life-long anticoagulation with vitamin $\mathrm{K}$ antagonists is recommended. However, although this approach has demonstrated a clear benefit in preventing recurrent thrombosis compared to off-treatment, recurrences of SVT or other thromboses may still occur in $15-20 \%$ of patients [20]. Although promising, there is still insufficient evidence to support a role for direct-acting oral anticoagulants in this setting [21].

In asymptomatic patients with a low or intermediate risk of disease according to the IPSS/DIPPS/DIPSS classifications, there is no evidence to support the value of disease-modifying therapy and observation alone is recommended. In contrast, cytoreductive treatment is indicated for patients with an intermediate or high risk of disease, and hydroxyurea or ruxolitinib are usually the first-line drugs of choice [22]. Although our patient had a low risk according to IPSS/DIPPS, there are studies demonstrating a good clinical response and safety profile in low-risk PMF patients treated with pegylated interferon, with high rates of splenic response, an improvement in constitutional symptoms, and the resolu- 
tion of leukocytosis and thrombocytosis, particularly in special populations including young and pregnant patients. In fact, interferon has been recommended as an option for symptomatic low- or intermediate-risk PMF patients by the National Comprehensive Cancer Network. Ultimately, the decision for which cytoreductive agent to use is based on individual factors such as comorbidities, risk status, symptom burden, age, and toxicity profile. In young patients, concern for hydroxyurea long-term effects associated with a known potential for durable responses, and disease modification associated with interferon led expert consensus guidelines to recommend interferon for first-line treatment in patients who are younger [23]. Based on these data, a decision to start cytoreductive therapy with pegylated interferon was taken.

In conclusion, although uncommon, MPN must be considered in the differential diagnosis of SVT, especially in the absence of cirrhosis or nearby malignancy. This case demonstrates that MPN may present with extensive SVT at its onset, even at early stages and in the absence of marked erythrocytosis, thrombocytosis, or concomitant hypercoagulable conditions. The presence of the JAK2 V617T mutation appears to be an important prothrombotic risk factor that can, per se, contribute to the development of large venous thrombosis.

\section{Statement of Ethics}

Informed consent was obtained from the patient.

\section{Conflict of Interest Statement}

The authors have no conflicts of interest to declare.

\section{Funding Sources}

The authors have no funding sources to declare.

\section{Author Contributions}

E.D., R.L. and P.C.M. were involved in the diagnostic work-up and conception and design of the work; E.D. wrote the manuscript; R.L. and G.M. performed a critical revision of the manuscript; G.M. also followed the patient in gastroenterology consultation; F.P. followed the patient in hematology consultation and critically reviewed the manuscript, providing expertise in the area of hematology; E.F. established anatomopathological diagnosis and critically reviewed the manuscript, providing expertise in the area of pathology. All authors read and approved the final version.

\section{References}

1 How J, Zhou A, Oh ST. Splanchnic vein thrombosis in myeloproliferative neoplasms: pathophysiology and molecular mechanisms of disease. Ther Adv Hematol. 2017 Mar;8(3):107-18.

2 Rajani R, Björnsson E, Bergquist A, Danielsson A, Gustavsson A, Grip O, et al. The epidemiology and clinical features of portal vein thrombosis: a multicentre study. Aliment Pharmacol Ther. 2010 Nov;32(9): 1154-62.

3 Smalberg JH, Arends LR, Valla DC, Kiladjian JJ, Janssen HL, Leebeek FW. Myeloproliferative neoplasms in Budd-Chiari syndrome and portal vein thrombosis: a meta-analysis. Blood. 2012 Dec;120(25): 4921-8.

4 De Stefano V, Vannucchi AM, Ruggeri M, Cervantes F, Alvarez-Larrán A, Iurlo A, et al. Splanchnic vein thrombosis in myeloproliferative neoplasms: risk factors for recurrences in a cohort of 181 patients. Blood Cancer J. 2016 Nov;6(11):e493.

5 Lavu S, Szuber N, Mudireddy M, Yogarajah M, Gangat N, Pardanani A, et al. Splanchnic vein thrombosis in patients with myeloproliferative neoplasms: the Mayo clinic experience with 84 consecutive cases. Am J Hematol. 2018 Mar;93(3):E61-4.

6 Chebli JM, Gaburri PD, Meirelles de Souza AF, Gonçalves Felga GE, Forn CG, Ferreira Pinto JR. Splenic-portal-mesenteric thrombosis with splenic infarction as first presentation of essential thrombocytosis. J Clin Gastroenterol. 2004 Jul;38(6):5401.

7 Berk DR, Ahmed A. Portal, splenic, and superior mesenteric vein thrombosis in a patient with latent essential thrombocythemia and hyperhomocysteinemia. J Clin Gastroenterol. 2006 Mar;40(3):227-8.

8 Marisavljevic D, Elezovic I, Bilanovic D, Petrovic N, Janjic M, Sefer D. Mesenteric and splenic vein thrombosis in a female patient with essential thrombocytosis and activated protein $\mathrm{C}$ resistance. Vojnosanit Pregl. 2003;60(2):227-31. Serbian.

9 Macías I. Massive upper gastrointestinal bleeding due to splenoportal axis thrombosis in a patient with a tested JAK2 mutation: A case report and review literature. Int J Surg Case Rep. 2016;28:93-6.

10 Vladareanu AM, Popov V, Bumbea H, Onisai M, Ilea A, Dobrea C, et al. Splanchnic vein thrombosis, the onset manifestation in JAK positive Chronic Myeloproliferative Disorders Neoplasms. J Med Life. 2011 JanMar;4(1):97-101.

11 de Suray N, Pranger D, Brenard R. Portal vein thrombosis as the first sign of a primary myeloproliferative disorder: diagnostic interest of the V617F JAK-2 mutation. A report of 2 cases. Acta Gastroenterol Belg. 2008 Jan-Mar;71(1):39-41.

12 Campos-Cabrera G, Campos-Cabrera V, Campos-Cabrera S, Campos-Villagómez JL, Romero-González A. Splanchnic vein thrombosis as a first manifestation of Primary myelofibrosis. Gac Med Mex. 2017; 153(4):537-40. Spanish.

13 Tremblay D, Vogel AS, Moshier E, Hoffman R, Kremyanskaya M, Zhou S, et al. Outcomes of splanchnic vein thrombosis in patients with myeloproliferative neoplasms in a single center experience. Eur J Haematol. 2020 Jan;104(1):72-3.

14 Rieu V, Ruivard M, Abergel A, Pezet D, Fouilhoux AC, Tournilhac O, et al. Mesenteric venous thrombosis. A retrospective study of 23 cases. Ann Med Interne (Paris). 2003 May;154(3):133-8. French. 
15 Sant'Antonio E, Guglielmelli P, Pieri L, Primignani M, Randi ML, Santarossa C, et al. Splanchnic vein thromboses associated with myeloproliferative neoplasms: an international, retrospective study on 518 cases. Am J Hematol. 2020 Feb;95(2):156-66.

16 Magaz M, Alvarez-Larrán A, Colomer D, López-Guerra M, García-Criado M, Mezzano G, et al. Next-generation sequencing in the diagnosis of non-cirrhotic splanchnic vein thrombosis. J Hepatol. 2021 Jan;74(1): 89-95. Spanish.

17 Barbui T, Thiele J, Gisslinger H, Kvasnicka HM, Vannucchi AM, Guglielmelli P, et al. The 2016 WHO classification and diagnostic criteria for myeloproliferative neo- plasms: document summary and in-depth discussion. Blood Cancer J. 2018 Feb;8(2): 15.

18 Guglielmelli P, Carobbio A, Rumi E, De Stefano V, Mannelli L, Mannelli F, et al. Validation of the IPSET score for thrombosis in patients with prefibrotic myelofibrosis. Blood Cancer J. 2020 Feb;10(2):21.

19 Koschmieder S, How I. How I Manage Thrombotic/Thromboembolic Complications in Myeloproliferative Neoplasms. Hämostaseologie. 2020 Feb;40(1):47-53. German.

20 Finazzi G, De Stefano V, Barbui T. Splanchnic vein thrombosis in myeloproliferative neoplasms: treatment algorithm 2018. Blood Cancer J. 2018 Jun;8(7):64.
21 Barbui T, De Stefano V, Falanga A, Finazzi G, Martinelli I, Rodeghiero F, et al. Addressing and proposing solutions for unmet clinical needs in the management of myeloproliferative neoplasm-associated thrombosis: A consensus-based position paper. Blood Cancer J. 2019 Aug;9(8):61.

22 Tefferi A. Primary myelofibrosis: 2019 up date on diagnosis, risk-stratification and management. Am J Hematol. 2018 Dec; 93(12):1551-60.

23 How J, Hobbs G. Use of Interferon Alfa in the Treatment of Myeloproliferative Neoplasms: Perspectives and Review of the Literature. Cancers (Basel). 2020 Jul;12(7): 1954. 